Zoological Research

\title{
湖北黑鹳越冬地的新发现 New Wintering Area of the Black Stork in Hubei, China
}

\author{
楼利高 ${ }^{1}$, 罗祖奎 ${ }^{2}$, 刘家武 ${ }^{1}$, 吴法清 ${ }^{1, *}$ \\ LOU Li-gao ${ }^{1}$, LUO Zu-kui ${ }^{2}$, LIU Jia-wu ${ }^{1}$, WU Fa-qing ${ }^{1, *}$ \\ (1. 华中师范大学 生命科学学院, 湖北 武汉 430079; \\ 2. 华东师范大学 生命科学学院, 上海市城市化生态过程与生态恢复重点实验室, 上海 200062) \\ 1. College of Life Sciences, Huazhong Normal University, Wuhan 430079, China;
}

2. College of Life Sciences, Shanghai Key Laboratory of Urbanization and Ecological Restoration, East China Normal University, Shanghai 200062, China)

关键词：湖北；仙桃；黑鹳；新越冬地

Key words: Hubei; Xiantao; Black Stork(Ciconia nigra); New wintering area

中图分类号: Q959.722 文献标识码: A 文章编号: 0254-5853-(2008)02-0223-02

黑鹳(Ciconia nigra)是世界性珍稀鸟类之一，在２002；Zheng ZX，2002)。但近几十年来，在世界 我国被列为一级保护动物, 曾经是一种分布广、较 范围内，其种群数量骤减: 目前在瑞典、丹麦、比 常见的大型涉离（Wang \& Xie，2004; Zheng GM， 利时、荷兰、芬兰等国已绝迹, 在德国、法国、朝

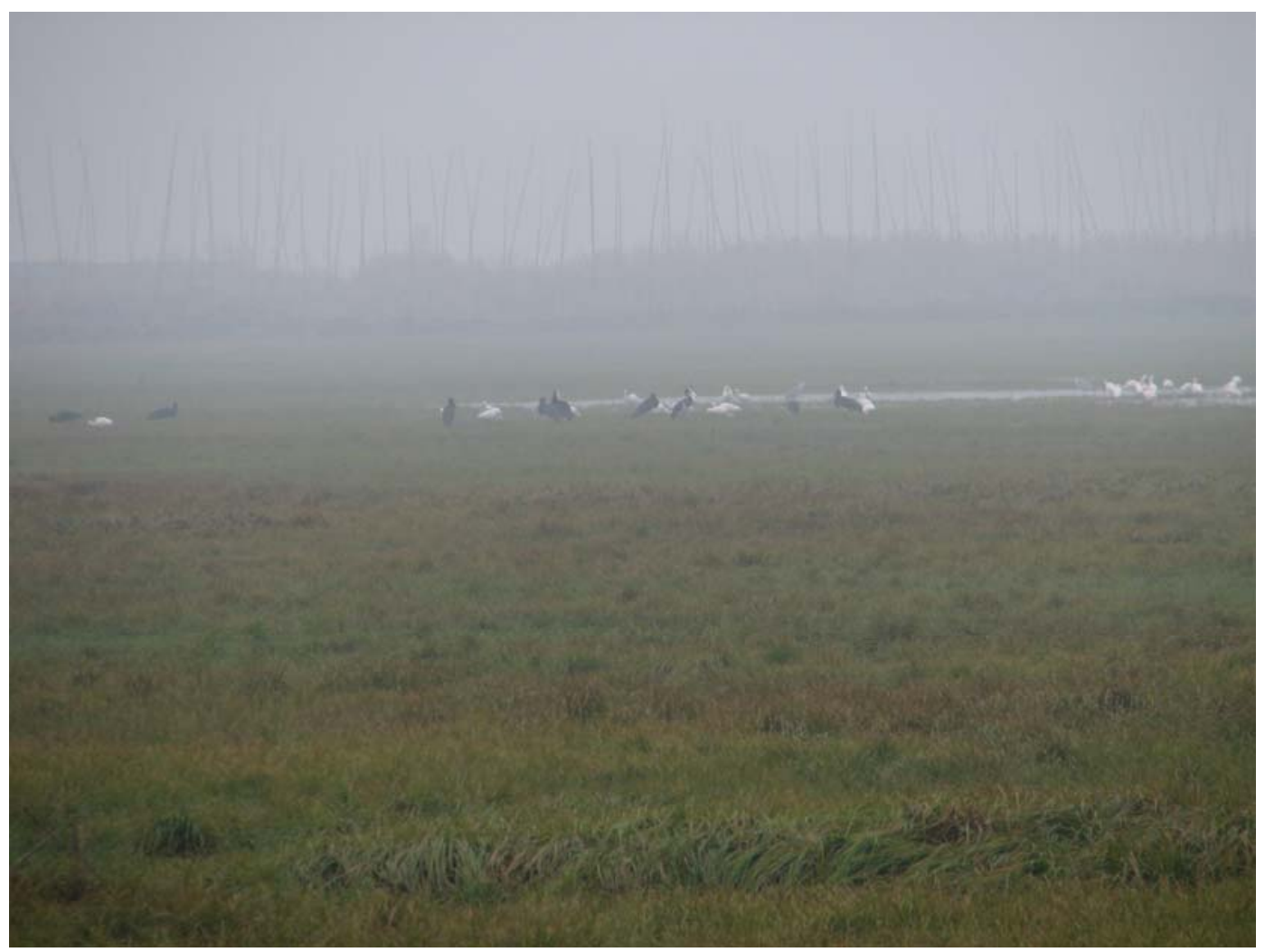

图 1 在湖北省仙桃市沙湖的南五湖发现的 9 只黑鹳在受食

Fig. 1 Nine foraging Black Storks were observed at Nanwu lake of Shahu lake in Xiantao city, Hubei province

收稿日期：2008-01-13；接受日期：2008-03-06

基金项目：HSBC-WWF 长江项目（0876); 湖北省科技基础条件平台建设专项项目(2004TZ06); 湖北省林业局资助项目

*通讯作者 (Corresponding author), Tel:027-67861190,E-mail:wufaqing886@126.com

第一作者简介: 楼利高(1983-), 男, 浙江诸暨人, 硕士, 主要从事鸟类生态和保护生物学研究。E-mail: loulg@mails.ccnu.edu.cn 
鲜半岛也已难见踪影。目前全世界仅存 1000 多个 繁殖对。在我国, 1999 年 6 月报道仅存 2000 只左 右, 2006 年 6 月降到 700-1000 只, 属濒危物种

(Wang \& Xie, 2004; Jin, 2005)。

2007 年 1 月 3 日一 1 月 7 日，在湖北省仙桃市 沙湖的南五湖 (Lat.55 m, $30^{\circ} 09.368^{\prime} \mathrm{N}$, $113^{\circ} 47.507^{\prime} \mathrm{E}$ ）进行冬候鸟考察，用 50 倍单筒望远 镜 (型号: Diascope 85 T $\times F L$ Carl Zeiss 20-60×) 观察水域鸟类时, 发现一群数量为 14 只的黑鹳种 群。这在该地区为首次发现, 而且如此多的数量也
是极为罕见的。自上世纪 80 年代在武汉市沉湖自 然保护区发现一群数量为 42 只的黑鹳种群 $(\mathrm{Hu}$, 1995 ) 之后, 就再也没有发现如此之大的黑鹳种群。 此次在该地区发现黑鹳的分布，与该地区生态 环境的大力保护是息息相关的。该地区基本野生环 境为芦苇从和湖泊(湖泊多、有长满茂盛野草的小 岛)。由于芦苇丛保护完好, 湖泊的水质未受污染, 因而能吸引涉禽来此受食、定居。对此, 我们应该 加强自然保护区建设, 为野生动植物的生存与繁衍 创造良好的环境。

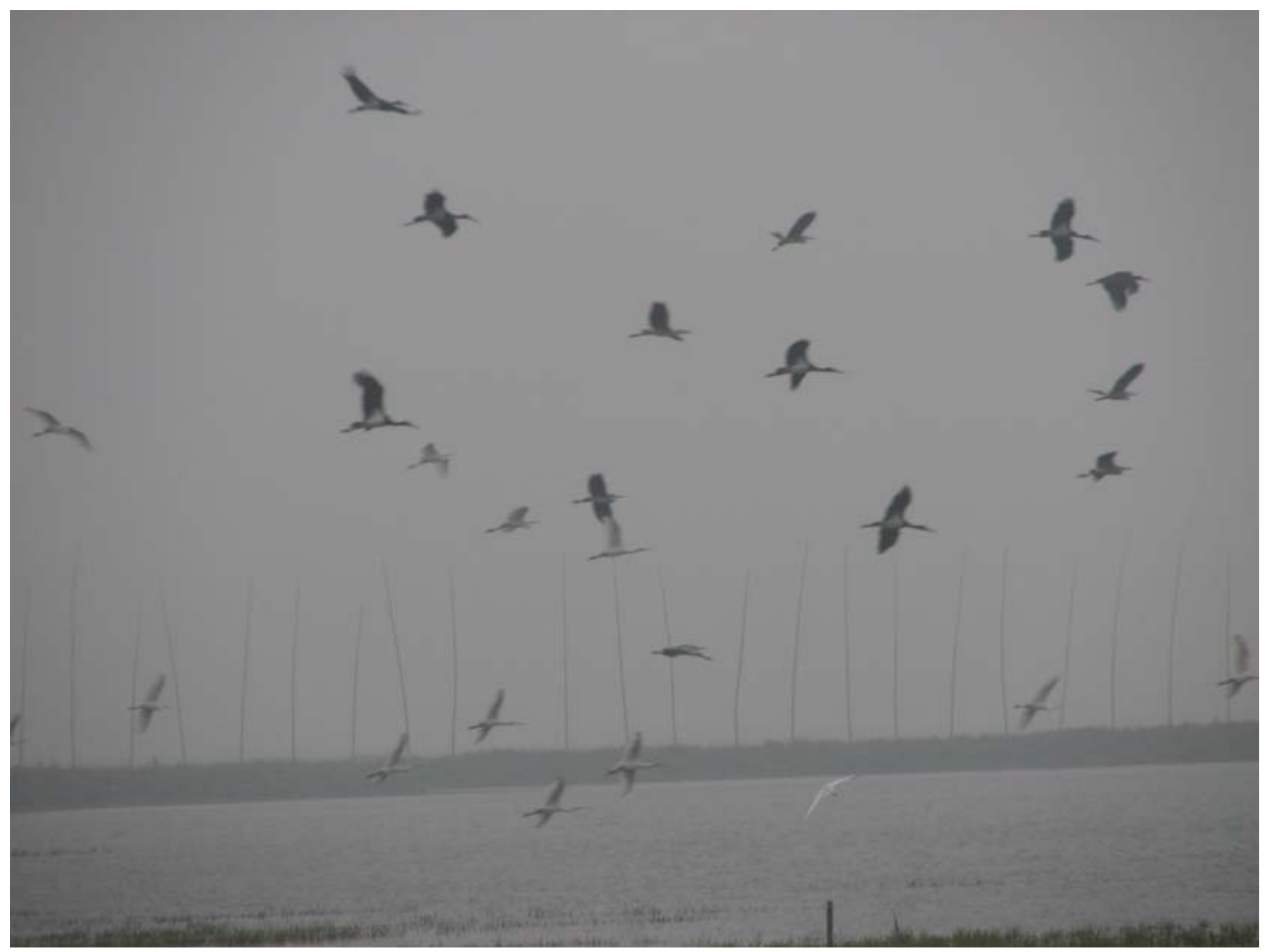

图 2 在湖北省仙桃市沙湖的南五湖发现的 12 只黑鹳受惊后起飞

Fig. 2 Twelve Black Storks took flight out of fright, at Nanwu lake of Shahu lake in Xiantao city, Hubei province

\section{参考文献:}

Hu HX,Wan H. 1995. Hubei Province Bird Multiplicity and its Protection Research[M]. Wuhan: Wuhan University Press.[胡鸿兴, 万 晖. 1995. 湖北鸟类多样性及保护研究. 武汉: 武汉大学出版社.] Jin TD. 2005. Ciconia nigra[EW]. http://www.ysdw.net/dispbbs.asp ?boardID $=38 \& \mathrm{ID}=1238$ \&page $=1$. 今天地. 2005 . 黑鹳 Ciconia nigra [EW].http://www.ysdw.net/dispbbs.asp?boardID=38\&ID=1238\&page $=1$.

Wang S, Xie Y. 2004. China Species Red List[M]. Beijing: Higher
Education Press.[汪 松, 解 炎. 2004. 中国物种红色名录. 北京: 高等教育出版社.]

Zheng GM. 2002. A Checklist on the Classification and Distribution of the Birds of the World[M]. Beijing: Science Press. [郑光美. 2002. 世界 鸟类分类与分步名录. 北京: 科学出版社.]

Zheng ZX. 2002. Chinese Birds System Retrieval[M]. Beijing: Science Press. [郑作新. 2002. 中国鸟类系统检索.第三版. 北京: 科学出版 社.] 